\title{
Greater Diversity or Fewer Whites? Disentangling Heterogeneity and Minority Share at Macro and Micro Levels
}

\author{
Maria Abascal \\ New York University
}

\author{
Flavien Ganter \\ Columbia University \\ WITH AN APPENDIX BY \\ Daniel Lacker \\ Columbia University
}

\author{
Delia Baldassarri \\ New York University
}

\begin{abstract}
Scholarship claims that diversity undermines trust and cooperation. Critiques focus on studies' inability to discern diversity's causal effects. In fact, most studies are unable to distinguish diversity-i.e., mixture-and minority share-e.g., percentage Black. We argue for preserving this distinction and identify obstacles to doing so. First, homogeneously minority communities are acutely underrepresented in North America and Europe, the settings of most diversity research. The second issue, a case of the ecological fallacy, concerns our inability to infer associations between individual outcomes and diversity from associations between macro-level outcomes and diversity. Much diversity research would be better served by using group share measures that align with the ingroup/outgroup theories they draw on to motivate research and explain findings. We clarify the data and analytic requirements for research that seeks to draw conclusions about diversity per se. Practically, the distinction between diversity and minority share is also relevant for policy.
\end{abstract}

Draft. March 2, 2023.

For valuable feedback, we are grateful to Elizabeth Bruch, Filiz Garip, and the participants of the Social Demography Seminar at Harvard University, the Center for Migration and Development at Princeton University, and the Seminar for Comparative Social Analysis (SOC 237) at UCLA. Thanks to Shannon Rieger for research support. This project received funding from the National Science Foundation [CAREER \#1845177] and the European Research Council [INTERACT Project \#639584]. Direct correspondance to Maria Abascal, Department of Sociology, New York University, 295 Lafayette Street, New York, NY 10012. Email: m.abascal@nyu.edu. 


\section{INTRODUCTION}

An active, cross-disciplinary, and controversial social science literature has linked diversity to undesirable outcomes including lower trust, civic participation, and public goods provision ${ }^{1}$ (for reviews, Dinesen and Sønderskov 2018; Dinesen et al. 2020; van der Meer and Tolsma 2014). Scholars have challenged these studies for inferring a causal effect of diversity without accounting for confounders (Abascal and Baldassarri 2015; Portes and Vickstrom 2011).

In this paper we draw attention to a different, and more fundamental, problem with most studies of racial/ethnic diversity: they do not distinguish racial/ethnic diversity from non-White or immigrant shares, conceptually or empirically. Although the reasons for this have not gone entirely unacknowledged(Kustov and Pardelli 2018; Schaeffer 2013; Uslaner 2010), scholars have generally failed to fully appreciate the consequences for data collection, modeling, and inference.

Analytical clarity is imperative to the study of diversity. This paper makes the case for preserving the distinction between diversity, i.e., heterogeneity, ${ }^{2}$ and nonWhite or immigrant shares, e.g., percentage Black or Latino in the United States or percentage foreign-born or visible minorities in Europe. Our contributions are twofold: first, we argue that most research on racial/ethnic diversity in North America and Europe is unable to disentangle heterogeneity from non-White or immigrant shares. A major obstacle stems from the underrepresentation of homogeneously non-White or homogeneously immigrant communities in most Western contexts. Without homogeneously non-White communities, homogeneous communities (and their residents) may be better off because they are homogeneous or because they are predominately White (or, more generally, advantaged). Aggravating this empirical limitation is the fact that most studies of diversity explain their results using theories that are predicated on in-group/out-group shares, not heterogeneity, and are thus not captured by measures of heterogeneity.

Our second contribution is to demonstrate that macro-level correlations between diversity and social outcomes are not especially informative of micro-level behavior. This case of the ecological fallacy has gone unnoticed in the diversity literature. We provide analytical proof that a macro-level association with diversity is consistent with at least two different micro-level processes. On the one

\footnotetext{
${ }^{1}$ We will use "prosociality" and "prosocial outcomes" as shorthand for the range of desirable outcomes to which diversity has been linked.

${ }^{2}$ Heterogeneity is greater the more groups are in a community and the more evenly distributed people are across those groups.
} 
hand, individual attitudes and behavior might be associated with diversity; on the other, they might be associated with group shares. This problem can be avoided by focusing on individual- or group-level outcomes, ${ }^{3}$ rather than population-level outcomes.

To conclude, we delineate the empirical requirements-in terms of data, analysis, and assumptions-for research to advance claims about associations with diversity.

\section{A REVIEW OF THE DIVERSITY LITERATURE}

Putnam (2007) famously reports a negative association between racial/ethnic diversity in U.S. census tracts and residents' reported trust in neighbors, concluding that people "hunker down" in the face of diversity, at least in the short term. Alesina and La Ferrara (2000) similarly document a negative association between diversity and reported trust across U.S. localities. Similar results obtain in Australia (Leigh 2006), the United Kingdom (Laurence 2011), Germany (Gundelach and Freitag 2014; Gundelach and Traunmüller 2014), and Denmark (Dinesen and Sønderskov 2015). And, cross-nationally, diversity is associated with lower average reported trust (Anderson and Paskeviciute 2006; Delhey and Newton 2005; Knack and Keefer 1997). Looking beyond trust, research has linked local diversity to lower participation in voluntary organizations (Alesina and La Ferrara 2002; Costa and Kahn 2003a), lower community attachment (Laurence and Bentley 2016), weaker civic norms (Knack and Keefer 1997), more military desertions(Costa and Kahn 2003b), and lower collective action (Vigdor 2004).

These studies have repeatedly attracted criticism for advancing causal claims about the effects of diversity without fully accounting for compositional differences between diverse and homogeneous communities and their residents. Examining Putnam's (2007) data, Abascal and Baldassarri (2015) find the negative association between diversity and trust disappears when they control for differences between the residents of diverse and homogeneous communities in terms of race/ethnicity, economic conditions, and residential stability. Race/ethnicity, in particular, plays a central role: non-Whites are more likely than Whites to live in diverse communities, and they also report lower trust. ${ }^{4}$

\footnotetext{
${ }^{3}$ Assuming there is not within-group heterogeneity in responses to diversity; we return to this where we make recommendations for future research.

${ }^{4}$ Other research has also documented lower reported trust among non-Whites, net of community characteristics (e.g., Alesina and La Ferrara 2002; Uslaner 2010).
} 
Additional work underscores marked socioeconomic differences between heterogeneous and homogeneous communities. For example, studies in the United States, the United Kingdom, and Europe find that heterogeneous communities are characterized by higher levels of economic deprivation which are, in turn, associated with lower trust. When studies control for economic factors, the negative association between diversity and trust is weakened or disappears (Fieldhouse and Cutts 2010; Ivarsflaten and Strømsnes 2013; Letki 2008; Marschall and Stolle 2004; Sturgis et al. 2011). ${ }^{5}$ Some studies that control for economic deprivation even find that diversity predicts higher reported trust under certain circumstances (Bécares et al. 2011; Tolsma et al. 2009).

Finally, residential segregation and thus limited opportunities for intergroup contact, rather than diversity, might be at the root of lower trust (Laurence 2017; Stolle et al. 2008; Sturgis et al. 2011; Uslaner 2012). In fact, field experiments on the effects of actual contact, rather than geographic proximity, find qualified support for the premise that contact reduces prejudice (Finseraas and Kotsadam 2017; Lowe 2021; Mousa 2020). Contact was also shown to increase native majorities' trust toward immigrants (measured behaviorally) in a field experiment in which soldiers were assigned to rooms with or without ethnic minorities (Finseraas et al. 2019).

Scholars will no doubt continue to debate whether correlations with diversity imply that diversity affects social outcomes, or whether they are compositional artifacts of deep-seated differences between diverse and homogeneous communities and their residents. We do not enter that fray here. Our concern precedes these debates: We call for preserving the analytic distinction between diversity, on the one hand, and non-White or immigrant share, on the other, against the overarching tendency to confuse the two, especially in contexts, like North America and Western Europe, where homogeneously non-White and homogeneously immigrant communities are underrepresented. For instance, in a recent review and meta-analysis of 87 studies on the association between diversity and self-reported trust, Dinesen et al. (2020) acknowledge this problem, noting that in almost all of the studies they consider, measures of diversity overlap strongly with non-White or immigrant shares. Regardless, the authors adopt a "broad" definition of diversity that encompasses both aspects. Leaning on this definition in their meta-analysis, the

${ }^{5}$ In addition, at the national level, the negative association between diversity and trust is weakened when quality of government and national affluence are held constant (Delhey and Newton 2005). 
authors count as measures of diversity the same measures that other authors have described as confounding factors, such as non-White share and immigrant share. By our count, almost $60 \%$ of the studies contributed one or more estimates based on group share to the meta-analysis. ${ }^{6}$ Pooling estimates from these studies, $\mathrm{Di}$ nesen et al. (2020) find a significant, modest association between measures of diversity and non-White or immigrant share, on the one hand, and lower trust, on the other. From this, the authors conclude, "the observed negative relationship thus first and foremost reflects a contextual effect... of ethnic diversity on social trust" (2020:455-456). This conclusion clashes with one of the author's own reading a few years earlier: recognizing that various diversity measures are essentially indistinguishable from "mere minority concentration," Schaeffer wrote, "Пmuch of the (European) research on ethnic diversity and social cohesion is actually about majority responses to minority concentration and tells us little about diversity effects per se" (2013:762).

\section{THE CASE FOR DISTINGUISHING DIVERSITY}

\section{FROM MINORITY SHARE}

Preserving the distinction between diversity and non-White or immigrant shares is imperative for conceptualizing and measuring theoretical constructs. This distinction may seem subtle, but the empirical expectations implied by claims about the effects of diversity diverge from those that follow from theories that hinge on non-White or immigrant shares, or out-group share generally.

\section{How Scholars Explain Associations with Diversity}

How do scholars motivate the conclusion that diversity engenders negative social outcomes? In most cases, negative associations between diversity and prosocial outcomes-whether at the individual (e.g., Putnam 2007) or aggregate level (e.g., Knack and Keefer 1997) - are explained with reference to individual attitudes and behavior toward in-group and out-group members. ${ }^{7}$

\footnotetext{
${ }^{6}$ About half of these only contributed estimates based on group share. Among those studies to contribute only estimates based on heterogeneity measures, most commonly a HerfindahlHirschman Index, over $70 \%$ are based on countries in North America, Western Europe, as well Australia and New Zealand, where we would expect heterogeneity and group share measures to overlap strongly.

${ }^{7}$ The exceptions are studies in political economy that invoke institutional explanations to account for associations between diversity and conflict as well as economic growth (e.g., Baldwin and Huber 2010; Fearon and Laitin 2003; Posner 2004).
} 
Most commonly, scholars draw on classic social psychological theories of intergroup conflict and threat. According to intergroup conflict/threat theories, spatial and social proximity intensify hostility between groups competing for scarce resources (Sherif et al. 1961; Blalock 1967). ${ }^{8}$ Reworking conflict/threat theories, Dinesen and Sønderskov (2015) posit that people read the presence of out-group members as a cue that the average, or generalized, other is more likely to be an out-group member, i.e., someone they mistrust (see also Dinesen and Sønderskov 2018). Mistrust and aversion toward out-group members could be rooted in competition or simply in ignorance, as implied by contact theory (Allport 1954). Putnam revisits the contact/conflict debate and advances a third possibility, "constrict theory," according to which "diversity might actually reduce both in-group and out-group solidarity" (2007:144).

According to other explanations, negative outcomes arise not from out-group hostility, but from coordination challenges across groups (Habyarimana et al. 2007). Trust and solidarity may be harder to develop toward out-group members, due to a lack of communal knowledge, social ties and coordination opportunities, as well as biased expectations concerning out-group behavior. Sanctioning might also be less effective toward out-group members, both because it is less likely to be meted out and because the costs of sanctioning by out-group members may be lower (Habyarimana et al. 2007). Finally, van der Meer and Tolsma (2014) have theorized that the absence of a shared culture with out-group neighbors may foster personal feelings of anomie.

Whether they stress competition, ignorance, opportunities or expectations, all of these theories rely on a categorical distinction between the in-group and the out-group and they imply that interactions with in-group versus out-group members produce better outcomes. (We therefore refer to these collectively as "in-group/out-group theories.") None of these arguments imply that people's attitudes or behavior respond to diversity, as we demonstrate next.

\section{Diverging Predictions of Diversity and Group Share Theories}

Studies that aim to test theories of in-group/out-group dynamics-or use them to explain their results-should use measures of group share, rather than measures of diversity, i.e., heterogeneity. This is not mere semantics. The predictions of in-group/out-group theories diverge from those implied by claims about diversity

\footnotetext{
${ }^{8}$ Under specific conditions, like equal status and repeated, intimate interactions, however, contact may dispel ignorance and improve relations (Allport 1954).
} 


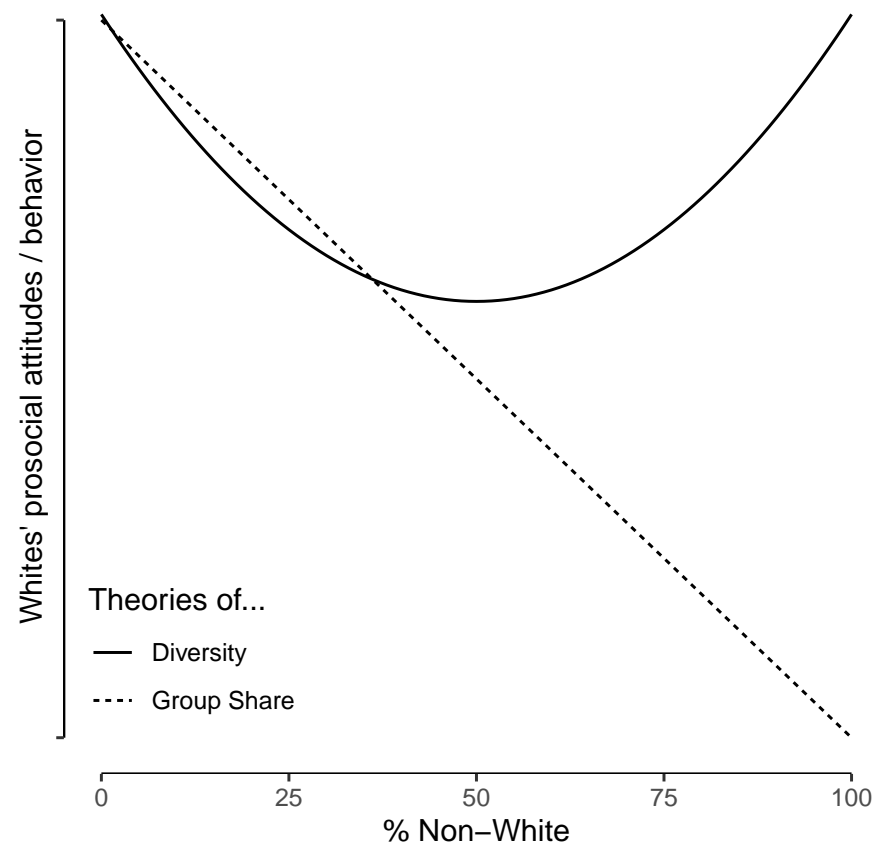

Figure 1: Hypothesized effects of diversity and group share on prosocial behavior for Whites in a world with two groups: Whites and non-Whites.

and by the use of diversity measures.

Consider a scenario with only two groups: Whites and non-Whites. Figure 1 plots the expected relationships between prosocial behavior and the proportion of non-Whites, for Whites. The straight, dashed line represents expectations based on in-group/out-group theories: as the share of non-Whites increases, prosocial behavior among Whites declines. The curved, solid line represents the relationship between non-White share and prosocial behavior, again for Whites, implied instead by claims about diversity. If diversity undermines prosociality, we should expect a non-monotonic, curvilinear relationship, in which prosociality is maximized in homogeneously White and homogeneously non-White contexts, and minimized where the population is evenly split. This is the relationship that papers tacitly test when they use heterogeneity indexes, like the HerfindahlHirschman Index (HHI), which are sensitive only to the number and relative sizes of groups, not their identities (for discussions, e.g., Posner 2004; Abascal and Baldassarri 2015). 
Figure 1 reveals where the two approaches diverge. In majority-White communities, both diversity and non-White/group share accounts predict that Whites become less prosocial as non-White share rises. In this part of the distribution, heterogeneity and non-White share increase in tandem. This is true until communities hit 50\% non-White. After that, more non-Whites generate less heterogeneity, not more, and the theoretical accounts diverge. If prosocial behavior hinges on out-group share, then Whites will continue to become less prosocial as non-White share rises. If, however, diversity drives Whites' behavior, Whites will become more prosocial as communities become more homogeneous, albeit homogeneously non-White. In other words, claims about diversity and diversity measures imply that Whites will be more prosocial in a community that is nearly $100 \%$ non-White than a community that is just $50 \%$ non-White. This prediction not only contradicts the in-group/out-group theories on which diversity studies draw, it is also implausible.

Why has the issue been overlooked? We believe two factors play a role. The first is widespread elision-both rhetorical and conceptual-between diversity and non-White or immigrant shares. Research from the United States suggests that, although people uniformly associate the term "diversity" with heterogeneity, some of them, including liberal Whites, also associate it with non-White share (Abascal et al. 2021; Abascal and Ganter 2022). ${ }^{9}$ The second factor stems from (1) the dearth of non-White scholars working in this area, combined with (2) the fact that homogeneous communities in North America and Europe, where this literature has flourished, are largely homogeneously White communities. For White scholars in majority-White contexts (and White readers), more diversity means more out-group members, i.e., more non-Whites. Equipped with theories of intergroup conflict/threat, it makes sense to them to expect that people will react badly to the presence of out-group members. But for, say, a Black American scholar, more diversity may correspond to more in-group members. And for her, the consequences of being around relatively more in-group members-especially if as a result of exclusion from White spaces-are neither obvious nor obviously desirable. The overlap between diversity and minority share in majority-White contexts has not only obscured the distinction between them, it also represents a major empirical challenge to research about diversity.

${ }^{9}$ In the United States, the association between diversity and non-White share was forged when the term "diversity" was mobilized to defend unpopular race-targeted programs and practices, like affirmative action (Berrey 2015). 


\section{OBSTACLE I: THE UNDERREPRESENTATION OF HOMOGENEOUSLY NON-WHITE COMMUNITIES}

The first empirical hurdle that faces research on diversity stems from the fact that in most Western European and North American countries, homogeneous communities are, by and large, predominately White communities (Uslaner 2012; Koopmans and Schaeffer 2016; Kustov and Pardelli 2018; Baldassarri and Abascal 2020). ${ }^{10}$ For example, more than $88 \%$ of all metropolitan and micropolitan statistical areas in the United States are majority-White, and about $12 \%$ are majoritynon-White (Figure 2). In fact, out of 990 areas in the United States, just 20 are more than $75 \%$ non-White. Majority-non-White communities are also underrepresented among census tracts (Abascal and Baldassarri 2015). A few scholars have also remarked on the underrepresentation of "majority-minority" communities in European countries and its implications for diversity research (Schaeffer 2013; Koopmans and Schaeffer 2016). More generally, rising diversity in North America and Western Europe is driven by non-White immigration (Baldassarri and Abascal 2020).

When homogeneous communities are mostly native, White communities, it is not possible to disentangle correlations with diversity from correlations with non-White or immigrant shares. Homogeneous communities might be better off not because they are homogeneous, but because they are homogeneously advantaged. The solution is to study contexts where different kinds of homogeneous communities are represented. Kustov and Pardelli (2018) do this in a study of Brazil; they find that diverse municipalities have lower public goods provision than homogeneously White communities, but higher public goods provision than homogeneously Black communities.

If diversity and minority share overlap in majority-White contexts, is the distinction relevant for research on North America and Western Europe? It is, for at least three reasons. First, in such contexts, diversity and out-group share coincide only for majority-group members. In our two-group example, for instance, an increase in diversity means more out-group members for Whites but fewer outgroup members for non-Whites. By ignoring this and drawing conclusions about the overall effects of diversity, studies assume (and imply) that the effects of diversity are the same for all groups. Despite relying on a predominately White sample, for example, Putnam's abstract reads, "in ethnically diverse neighborhoods residents of all races tend to 'hunker down" (2007:137). This tendency to gener-

\footnotetext{
${ }^{10}$ Or homogeneously majority-group, or homogeneously native-born communities.
} 


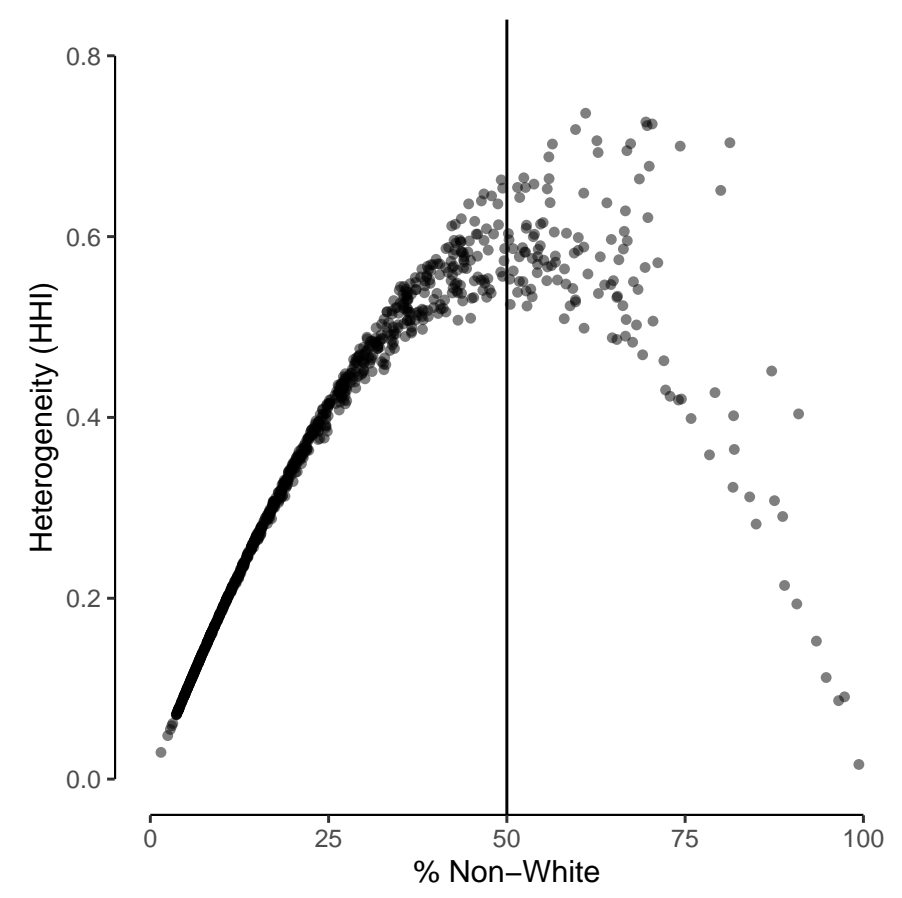

Figure 2: Association between diversity and non-White share: U.S. metropolitan and micropolitan statistical areas. Diversity, i.e., heterogeneity, represented by a HerfindahlHirshman index based on five groups: Whites, Blacks, Latinos, Asians, and all others. Source: American Community Survey (2013-2017). 
alize about the effects of diversity stands in contrast with experimental studies on intergroup contact, which focus on how members of one group (typically the majority) reacts to contact with out-group members, rather than relying on designs or drawing conclusions about the synthetic effects of a generic "diversity" (e.g., Finseraas et al. 2019).

The distinction between diversity and minority share is also relevant for majority-White countries, many of which are witnessing the growth of non-White and immigrant populations. This is why many scholars have become interested in the effects of diversity to begin with. As a result of demographic changes, even majority-White countries will come to have more majority-minority communities, that is, communities where diversity and minority share are at odds. This is already the case for sub-contexts such as schools and workplaces. Thus, the distinction between diversity and minority share will become increasingly important moving forward.

Finally, as we have shown, the theories mobilized in studies of diversity in fact make predictions about out-group share and exposure to it. Group share measures-rather than heterogeneity measures-are a better operationalization of the theoretical constructs embedded in conflict, threat, and other theories used in studies of diversity.

Although we are not the first scholars to recognize the overlap between heterogeneity and non-White or immigrant shares, empirical research has yet to effectively address this limitation (Kustov and Pardelli 2018 are an exception). Moreover, the underrepresentation of homogeneously non-White and immigrant communities is not the only obstacle for diversity research.

\section{OBSTACLE II: THE PROBLEM OF AGGREGATION}

Social scientists have long been warned about the risks of drawing conclusions at the individual level from associations at the ecological level ("ecological fallacy"; Robinson 1950), and a rich literature attempts to identify methods to circumvent this problem (Goodman 1953, 1959; King 1997). The same caveat applies here: an aggregate-level association with diversity can arise from different micro-level processes, and it is not unequivocal evidence that individual residents are less prosocial in more diverse communities. This is, however, what prior studies imply, when they explain aggregate associations by claiming that individuals respond to diversity or when they invoke aggregate associations to justify the use of diversity indexes in individual-level analyses. 
What could explain an aggregate association between diversity and prosocial behavior? Figure 3 illustrates several possible scenarios (of many) and reports group-level and population-level associations for each. First, consider the case where individual prosociality is correlated with diversity at the individual level and across groups (panel A). The curved dotted and dashed lines depict the associations between group share and prosociality among White and non-White individuals, as implied by studies that frame their questions and findings in terms of associations with "diversity" at the individual level or use diversity indexes in individual-level analyses. Here, members of both groups are less prosocial in heterogeneous communities, and they are more prosocial behavior in homogeneous communities, whether homogeneously White or homogeneously nonWhite. The solid grey line depicts aggregate levels of prosocial behavior in this case, obtained by averaging over the group-level curves. The macro-level association between prosocial behavior and non-White share is curvilinear. From an aggregate perspective, the macro-level association makes sense: everyone is least prosocial in the most diverse communities, and as a result, aggregate levels of prosocial behavior are also lowest in these communities.

However, a different micro-level process is also consistent with a curvilinear association between group share and prosocial behavior at the macro level. In Panel B, prosociality for individuals in both groups is correlated not with diversity but with out-group share. The greater the share of non-Whites, the less prosocial Whites are and the more prosocial non-Whites are. This micro-level process also yields a curvilinear association between group share and aggregate prosocial behavior wherein prosocial behavior is lower in heterogeneous communities and higher in homogeneous ones. This happens because individuals are less prosocial as their in-groups come to represent a smaller and smaller share of a community. ${ }^{11}$

In the appendix, we develop and generalize on these examples, showing that a curvilinear association between group share and prosocial behavior at the macro level-the kind of association that might suggest a role for diversity-tells us little about the micro-level process that produced it. At the aggregate level, prosociality may vary across neighborhoods not only because residents are exposed to different racial compositions, but also because they may react differently to variations in racial composition. Both dynamics are simultaneous and indistinguishable at the aggregate level. Panel C in Figure 3 even illustrates a case where prosociality is in-

${ }^{11}$ Winter and Zhang (2018), in their field experiment on social sanctioning-an antisocial behavior-remark on this possibility when extrapolating from their individual-level results. 


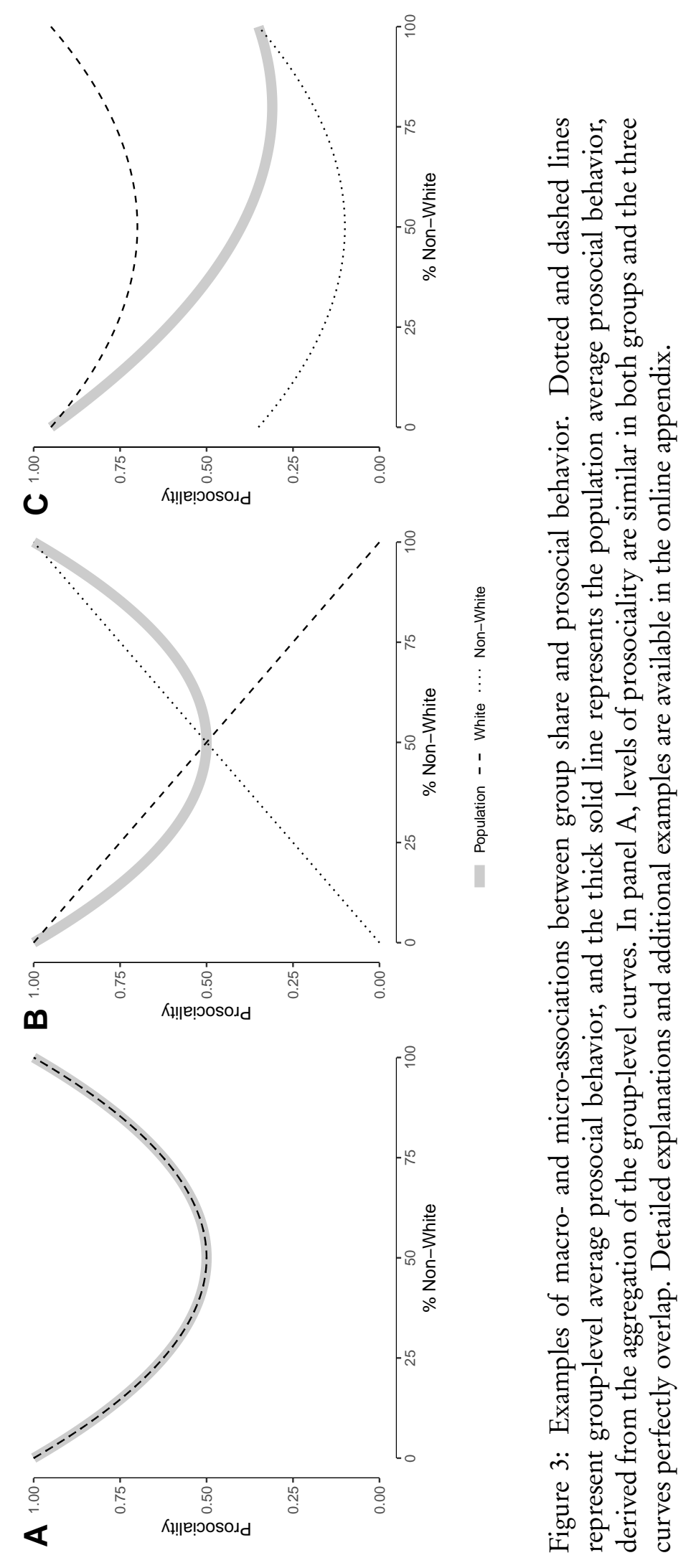


deed associated with diversity among both groups, but because baseline prosociality differs between groups, prosociality declines monotonically with non-White share at the macro level. In settings with more than two groups, or where individuals behave differently within identifiable groups, the connection between individual-level and population-level associations is even looser.

Note that our recommendation to examine micro data does not address questions regarding causal inference and potential confounding. Abascal and Baldassarri, for example, show that the association identified by Putnam (2007) is accounted for by the fact that "nonwhites report lower trust and are overrepresented in heterogeneous communities" (Abascal and Baldassarri 2015:722).

\section{THE WAY FORWARD: HOW TO STUDY DIVERSITY AT MACRO AND MICRO LEVELS}

How can research that is genuinely interested in investigating and advancing claims about diversity per se overcome the obstacles we have identified? First, to claim an outcome is associated with diversity at a population level, one needs to observe the full range of homogeneous communities, and not only (or overwhelmingly) homogeneously native, White communities. This is difficult, but not impossible in observational studies of real-world communities. For one, researchers can look beyond North America and Western Europe. Kustov and Pardelli (2018) study of public goods provision across Brazilian municipalities is an excellent example, and it is not the only one (see also Levine et al. 2014). In fact, studies in developing countries that predate most of those covered here have fruitfully investigated the relationship between ethnic diversity and societal problems, such as stalled economic growth (Easterly and Levine 1997; Collier 1998; Posner 2004) and violent conflict (Fearon and Laitin 2003; Blattman and Miguel 2010). These studies, most of which make cross-national comparisons, focus on parts of the world, particularly Africa, with the full range of relevant groups represented in both homogeneous and heterogeneous communities as well as longstanding histories of ethnic diversity (Posner 2004).

Even within North American or European countries, researchers could home in on areas within which lower-level communities span the spectrum of racial compositions. Recall that less than $12 \%$ of all metropolitan and micropolitan statistical areas in the United States are more than 50\% non-White. In major U.S. cities, like New York and Chicago, however, non-White neighborhoods are the 
norm. Of 2,111 census tracts in New York City, ${ }^{12}$ for example, about two-thirds (68.4\%) are more than 50\% non-White. In Chicago, that figure is $67.5 \%$.

Scholars can also leverage experimental designs to "create" the kinds of "communities" that are underrepresented in the real world and also to evaluate causal claims about the effects of diversity. For example, a researcher could randomly assign participants to groups that range in composition from predominately White, to heterogeneous White/Black, to predominately Black. Experimental researchers have explored behavior in homogeneous and heterogeneous settings (Habyarimana et al. 2007) and systematically varied the number and characteristics of ingroup and out-group members (Adida et al. 2016). Surprisingly, these designs rarely incorporate homogeneously minority groups (Gereke et al. 2021). Even in the largely experimental organizational literature on diversity and its relationship to deliberation, decision-making and performance (for a review, Carter and Phillips 2017), experiments on racial/ethnic diversity operationalize homogeneity using homogeneously majority groups, most commonly homogeneously White ones (e.g., Sommers 2006; Antonio et al. 2004; Levine et al. 2014).

To study associations with diversity at the group level-say, for Whitesresearchers must observe a substantial number of homogeneously non-White or homogeneously immigrant communities as well as a substantial number of Whites in homogeneously White and homogeneously non-White communities. This is not easy: the individual members of any group are, by definition, underrepresented in homogeneously out-group communities. If the researcher does not want to assume, reasonably so, that Whites react similarly to all non-White groups, she must further observe a substantial number of Whites in specifically homogeneously Asian communities, homogeneously Black communities, and so on. Or she can restrict her claims to Whites in diverse White/Asian communities, for example, a constraint that may prove unworkable given the rise of multiethnic communities (Zhang and Logan 2016).

Importantly, group-level analyses require researchers to assume that withingroup variation is negligible, i.e., that sub-groups that cannot be identified in the data (e.g., in many cases, Mexican and Cuban Americans) do not vary widely in how they react to community composition from each other or from the larger group that can be identified (e.g., Latinos). If they do, the obstacles that face "group-level" analyses are indistinguishable from those that face population-level

\footnotetext{
${ }^{12}$ For both cities, numbers are based on tracts with more than 100 inhabitants.
} 
analyses.

Alternatively, individual-level data can be used to investigate associations with diversity for all individuals, regardless of background. Such research must clear additional hurdles. Say a researcher is studying a context with just two groupsWhites and Blacks; to avoid the implausible assumption that Whites respond to Blacks in the same way that Blacks respond to Whites (see Uslaner 2012), she would need to observe a substantial number of Whites in predominately Black communities and a substantial number of Blacks in homogeneously White communities. Where homogeneously Black communities are scarce, the first set of observations will be exceedingly difficult to come by. With more groups, the difficulty grows exponentially. With three groups-say, Whites, Blacks, and Latinosa researcher would need substantial numbers of observations of (1) Whites in predominately White, (2) predominately Black, and (3) predominately Latino communities; (4) Blacks in predominately Black, (5) predominately White, and (6) predominately Latino communities; and (7) Latinos in predominately Latino, (8) predominately White, and (9) predominately Black communities, among others. A researcher who wanted to study the five major U.S. racial/ethnic would need substantial numbers of observations in more than 25 cells.

In sum, research that seeks to study and advance claims about associations with diversity among individuals, without reference to their race/ethnicity, must clear an exceptionally high bar. Although many studies share this ambition (see Dinesen et al. 2020), most fall short.

\section{CONCLUSION}

3,600 journal articles published in $1999^{13}$ refer to "racial diversity." ${ }^{14}$ In 2020, that number was 17,300 . In that interval, the number of articles published annually about diversity increased almost fivefold, and this was not due to increases in publishing on the topic of race/ethnicity. ${ }^{15}$

Research has advanced myriad claims about the effects diversity for trust, participation, and cooperation. This research has been criticized for advancing causal claims without compelling causal identification strategies. However, the diversity

${ }^{13}$ The year Alesina et al. (1999) was published.

${ }^{14}$ Or "ethnic diversity," or "racial/ethnic diversity," or "ethnoracial diversity."

${ }^{15}$ Indeed, in this same period, the number of journal articles published annually that refer to "race" or "ethnicity" (or "race/ethnicity," or "ethnoracial") declined. 
literature suffers from a more elementary problem: most studies cannot distinguish diversity from non-White or immigrant shares, conceptually or empirically. Instead, scholars frame their questions and results using theories that make predictions about group shares and that are not captured by diversity measures.

This paper has identified two obstacles to distinguishing diversity from minority share, and in so doing, clarified best practices for diversity research moving forward. The first obstacle stems from the underrepresentation of homogeneously non-White or homogeneously immigrant communities, especially in North America and Europe, where most diversity research is based. The second obstacle concerns the inability to infer micro-level associations with diversity from macro-level associations, in line with insights from the ecological inference literature.

To recover the association between prosociality and diversity for a specific racial/ethnic group, say Whites, research requires data on sufficient numbers of Whites in homogeneously White and homogeneously non-White communities. To make inferences about the association between prosociality and diversity for individuals, regardless of race/ethnicity, research requires data on sufficient numbers of Whites in homogeneously White and homogeneously non-White communities and sufficient numbers of non-Whites in homogeneously White and homogeneously non-White communities (in a two-group scenario). If we think a context is better understood in terms of three, four, five or more groups, rather than two (e.g., White/non-White), the types of observations we need grow exponentially. Without these observations, claims about diversity should be appropriately restrained. The result, ironically, is that to understand diversity in diverse groups, we should not rely primarily on measures of diversity.

\section{Toward a Theory of Diversity}

Assume future work addresses the obstacles we have identified and finds that prosociality among individuals-whether from one or multiple racial/ethnic groups-is associated with diversity, not group shares. Whether the association is indicative of a causal relationship-for example, because it draws on experimental evidence-or merely suggestive of one, this work will come up short looking for theories that can account for individual responses to diversity, as opposed to in-group/out-group shares. We propose three possibilities. They are neither exhaustive nor exclusive, and these processes might work together with each other and with others not considered. 
First, people might be more wary of sanctioning in homogeneous communities, where a univocal normative order is inferred from racial/ethnic homogeneity. Sanctioning is effective at promoting prosocial behavior, and co-ethnics might be better equipped to find, and hence sanction, each other (Habyarimana et al. 2007). If sanctioning-real or perceived-is a function not just of co-ethnicity, but of inferred normative homogeneity within communities, then individuals might behave more prosocially where (they think) their neighbors are more similar to each other.

Second, prosocial behavior could be depressed in diverse communities as a result of rank ambiguity between individuals from different backgrounds. Conflict is more likely to emerge between individuals whose relative symbolic, economic, or political status is ambiguous (Gould 2003). If status is also constructed on the basis of numbers (Koopmans and Schaeffer 2015; see also Legewie and Schaeffer 2016), the relative status of two individuals from different groups is more ambiguous where those groups are evenly split. Here, interpersonal conflict is more likely.

Third, people might engage in prosocial behavior where they expect others will do the same. If expectations are affected not just by others' identities, but also by community composition, then expectations and subsequent behavior could assume a curvilinear shape across group shares. Take the hypothetical example of Whites in White/Black neighborhoods. If Whites believe other Whites become less prosocial as Black share grows, and they believe Blacks become more prosocial as Black share grows, then Whites in 50\% White/50\% Black neighborhoods will think their neighbors are least prosocial, and they will follow suit.

\section{The Practical Implications of Diversity Research}

The conclusions of diversity research have implications outside academia, where studies on this topic have garnered considerable attention. For example, Putnam (2007) was covered in both mainstream and right-wing media, and it continues to circulate on far-right corners of the internet. Coverage of this research has tended to converge on similar policy lessons: Because diversity has negative consequences, then policies should aim to curb interracial mixing (Krikorian 2017); at the very least, they should not promote it (e.g., Thernstrom et al. 2012).

Consider the policy lessons that would flow from a different conclusion: not that people "of all races" report lower trust as communities become more mixed, but that Whites report lower trust as the share of non-Whites in their communities 
grows. The second interpretation might set off a quest to allay Whites' biases toward non-Whites or mitigate its consequences, not to curb the number of nonWhites admitted into majority-White schools, neighborhoods, or countries.

These recommendations are at odds, but they follow from subtly different interpretations of the same empirical patterns. The point is not that scholars should cease to make claims about diversity, because these claims support rightwing policies. ${ }^{16}$ The point is that they need to distinguish diversity from minority share, because this distinction has practical implications, as well as conforming to best practices of aligning theoretical constructs and empirical measures.

\section{REFERENCES}

Abascal, Maria and Delia Baldassarri. 2015. "Love Thy Neighbor? Ethnoracial Diversity and Trust Reexamined." American Journal of Sociology 121(3):722782.

Abascal, Maria and Flavien Ganter. 2022. "Know it when you see it? The qualities of the communities people describe as 'diverse'." City E Community 21(4):319339.

Abascal, Maria, Janet Xu, and Delia Baldassarri. 2021. "People use both heterogeneity and minority representation to evaluate diversity." Science Advances 7(11).

Adida, Claire L., David D. Laitin, and Marie-Anne Valfort. 2016. Why Muslim Integration Fails in Christian-Heritage Societies. Cambridge: Harvard University Press.

Alesina, Alberto, Reza Baqir, and William Easterly. 1999. "Public Goods and Ethnic Divisions.” Quarterly Journal of Economics 114(4):1243-1284.

Alesina, Alberto and Eliana La Ferrara. 2000. "Participation in Heterogeneous Communities." Quarterly Journal of Economics 115(3):847-904.

Alesina, Alberto and Eliana La Ferrara. 2002. "Who trusts others?" Journal of Public Economics 85(2):207-234.

Allport, Gordon Willard. 1954. The Nature of Prejudice. Reading, MA: AddisonWesley.

\footnotetext{
${ }^{16}$ Americans on the ideological left are no less guilty of conflating "diversity" with minority share; in fact, experimental evidence suggests they might be especially prone to doing so (Abascal et al. 2021).
} 
Anderson, Christopher J. and Aida Paskeviciute. 2006. "How Ethnic and Linguistic Heterogeneity Influence the Prospects for Civil Society: A Comparative Study of Citizenship Behavior." The Journal of Politics 68(4):783-802.

Antonio, Anthony Lising, Mitchell J. Chang, Kenji Hakuta, David A. Kenny, Shana Levin, and Jeffrey F. Milem. 2004. "Effects of Racial Diversity on Complex Thinking in College Students.” Psychological Science 15(8):507-510.

Baldassarri, Delia and Maria Abascal. 2020. "Diversity and prosocial behavior." Science 369(6508):1183-1187.

Baldwin, Kate and John D. Huber. 2010. "Economic versus Cultural Difference: Forms of Ethnic Diversity and Public Goods Provision." American Political Science Review 104(4):644-662.

Bécares, Laia, Mai Stafford, James Laurence, and James Nazroo. 2011. "Composition, Concentration and Deprivation: Exploring their Association with Social Cohesion among Different Ethnic Groups in the UK." Urban Studies 48(13):2771-87.

Berrey, Ellen. 2015. The Enigma of Diversity: The Language of Race and the Limits of Racial Justice. Chicago and London: University of Chicago Press.

Blalock, Hubert M. 1967. Toward a Theory of Minority-Group Relations. New York: John Wiley.

Blattman, Christopher and Edward Miguel. 2010. "Civil war." Journal of Economic Literature 48(1):3-57.

Carter, Ashli B. and Katherine W. Phillips. 2017. "The Double-Edged Sword of Diversity: Toward a Dual Pathway Model." Social and Personality Psychology Compass 11(5):1-13.

Collier, Paul. 1998. The political economy of ethnicity. Washington, DC: World Bank.

Costa, Dora L. and Matthew E. Kahn. 2003a. "Cowards and Heroes: Group Loyalty in the American Civil War." Quarterly Journal of Economics 118(2):519548.

Costa, Dora L. and Matthew E. Kahn. 2003b. "Civic Engagement and Community Heterogeneity: An Economist's Perspective." Perspectives on Politics 1(1):103-111.

Delhey, Jan and Kenneth Newton. 2005. "Predicting Cross-national Levels of Social Trust: Global Pattern or Nordic Exceptionalism?” European Sociological Review 21(4):311-327.

Dinesen, Peter T. and Kim M. Sønderskov. 2015. "Ethnic Diversity and Social Trust: Evidence from the Micro Context." American Sociological Review 80(3):550-573.

Dinesen, Peter T. and Kim M. Sønderskov. 2018. "Ethnic Diversity and Social Trust: A Critical Review of the Literature and Suggestions for a Research 
Agenda." In Oxford Handbook of Social and Political Trust, edited by Eric M. Uslaner, pp. 175-204. Oxford University Press.

Dinesen, Peter T., Merlin Schaeffer, and Kim Mannemar Sønderskov. 2020. "Ethnic Diversity and Social Trust. A Narrative and Meta-Analytical Review." Annual Review of Political Science 23:441-465.

Easterly, William and Ross Levine. 1997. "Africa's Growth Tragedy: Policies and Ethnic Divisions.” Quarterly Journal of Economics 112(4):1203-1250.

Fearon, James D. and David D. Laitin. 2003. "Ethnicity, insurgency, and civil war." American Political Science Review 97(1):75-90.

Fieldhouse, Edward and David Cutts. 2010. "Does Diversity Damage Social Capital? A Comparative Study of Neighbourhood Diversity and Social Capital in the US and Britain." Canadian Journal of Political Science 43(2):289-318.

Finseraas, Henning, Torbjørn Hanson, Åshild A. Johnsen, Andreas Kotsadam, and Gaute Torsvik. 2019. "Trust, ethnic diversity, and personal contact: A field experiment." Journal of Public Economics 173:72-84.

Finseraas, Henning and Andreas Kotsadam. 2017. "Does personal contact with ethnic minorities affect anti-immigrant sentiments? Evidence from a field experiment.” European Journal of Political Research 56(3):3703-3722.

Gereke, Johanna, Max Schaub, and Delia Baldassarri. 2021. "Immigration, Integration, and Cooperation: Experimental Evidence from a Public Goods Game in Italy." Working paper.

Goodman, Leo. 1953. "Ecological Regression and Behavior of Individuals." American Sociological Review 18(6):663-664.

Goodman, Leo. 1959. "Some Alternatives to Ecological Correlation." American Journal of Sociology 64(6):610-625.

Gould, Roger V. 2003. Collision of Wills: How Ambiguity About Social Rank Breeds Conflict. Chicago and London: University of Chicago Press.

Gundelach, Birte and Markus Freitag. 2014. "Neighbourhood diversity and social trust: An empirical analysis of interethnic contact and group-specific effects." Urban Studies 51(6):1236-1256.

Gundelach, Birte and Richard Traunmüller. 2014. "Beyond generalised trust: Norms of reciprocity as an alternative form of social capital in an assimilationist integration regime." Political Studies 62(3):596-617.

Habyarimana, James, Macartan Humphreys, Daniel N. Posner, and Jeremy M. Weinstein. 2007. "Why Does Ethnic Diversity Undermine Public Goods Provision?” The American Political Science Review 101(4).

Ivarsflaten, Elizabeth and Kristin Strømsnes. 2013. "Inequality, Diversity and Social Trust in Norwegian Communities." Journal of Elections, Public Opinion and Parties 23(3):322-342. 
King, Gary. 1997. A Solution to the Ecological Inference Problem. Princeton: Princeton University Press.

Knack, Stephen and Philip Keefer. 1997. "Does Social Capital Have An Economic Payoff? A Cross-Country Investigation." Quarterly Journal of Economics 112(4):1251-1288.

Koopmans, Ruud and Merlin Schaeffer. 2015. "Relational Diversity and Neighborhood Cohesion: Unpacking Variety, Balance, and In-group Size.” Social Science Research 53:162-176.

Koopmans, Ruud and Merlin Schaeffer. 2016. "Statistical and Perceived Diversity and Their Impacts on Neighborhood Social Cohesion in Germany, France and the Netherlands." Social Indicators Research 125(3):853-883.

Krikorian, Mark. 2017. "The Immigration Dodge." Wall Street Journal, March 25.

Kustov, Alexander and Giuliana Pardelli. 2018. "Ethnoracial Homogeneity and Public Outcomes: The (Non)effects of Diversity." American Political Science Review 112(4):1096-1103.

Laurence, James. 2011. “The Effect of Ethnic Diversity and Community Disadvantage on Social Cohesion: A Multi-Level Analysis of Social Capital and Interethnic Relations in UK Communities.” European Sociological Review 27(1):70-89.

Laurence, James. 2017. "Wider-community Segregation and the Effect of Neighbourhood Ethnic Diversity on Social Capital: An Investigation into IntraNeighbourhood Trust in Great Britain and London.” Sociology 51(5):10111033.

Laurence, James and Lee Bentley. 2016. "Does Ethnic Diversity Have a Negative Effect on Attitudes Towards the Community? A Longitudinal Analysis of the Causal Claims Within the Ethnic Diversity and Social Cohesion Debate." European Sociological Review' 32(1):54-67.

Legewie, Joscha and Merlin Schaeffer. 2016. "Contested Boundaries: Explaining Where Ethnoracial Diversity Provokes Neighborhood Conflict." American Journal of Sociology 122(1):125-161.

Leigh, Andrew. 2006. "Trust, Inequality and Ethnic Heterogeneity." Economic Record 82(258):268-280.

Letki, Natalia. 2008. "Does Diversity Erode Social Cohesion? Social Capital and Race in British Neighbourhoods.” Political Studies 56(1):99-126.

Levine, Sheen S., Evan P. Apfelbaum, Mark Bernard, Valerie L. Bartlet, Edward J. Zajac, and David Stark. 2014. "Ethnic Diversity Deflates Price Bubbles." Proceedings of the National Academy of Sciences 111(52):18524-18529.

Lowe, Matt. 2021. "Types of Contact: A Field Experiment on Collaborative and Adversarial Caste Integration.” American Economic Review 111(6):1807-1844. 
Marschall, Melissa J. and Dietlind Stolle. 2004. "Race and the City: Neighborhood Context and the Development of Generalized Trust." Political Behavior 26(2):125-153.

Mousa, Salma. 2020. "Race and the City: Neighborhood Context and the Development of Generalized Trust.” Science 369(6505):866-870.

Portes, Alejandro and Erik Vickstrom. 2011. "Diversity, Social Capital, and Cohesion." Annual Review of Sociology 37:461-479.

Posner, Daniel N. 2004. "The political salience of cultural difference: Why Chewas and Tumbukas are allies in Zambia and adversaries in Malawi." American Political Science Review 98(4):529-545.

Putnam, Robert D. 2007. "E Pluribus Unum: Diversity and Community in the Twenty-first Century." Scandinavian Political Studies 30(2):137-174.

Robinson, William S. 1950. "Ecological correlations and the behavior of individuals." American Sociological Review 15(3):351-357.

Schaeffer, Merlin. 2013. "Ethnic diversity, public goods provision and social cohesion: Lessons from an inconclusive literature.” WZB Discussion Paper SP VI 2013-103.

Sherif, Muzafer, B. Jack Harvey, O. J. White, William R. Hood, and Carolyn W. Sherif. 1961. Intergroup Conflict and Cooperation: The Robbers Cave Experiment. Norman.

Sommers, Samuel R. 2006. "On Racial Diversity and Group Decision Making: Identifying Multiple Effects of Racial Composition on Jury Deliberations." Journal of Personality and Social Psychology 90(4):597-612.

Stolle, Dietlind, Stuart Soroka, and Richard Johnston. 2008. "When Does Diversity Erode Trust? Neighborhood Diversity, Interpersonal Trust and the Mediating Effect of Social Interactions.” Political Studies 56(1):57-75.

Sturgis, Patrick, Ian Brunton-Smith, Sanna Read, and Nick Allum. 2011. "Does Ethnic Diversity Erode Trust? Putnam's 'Hunkering Down' Thesis Reconsidered." British Journal of Political Science 41(1):57-82.

Thernstrom, Abigal, Stephan Thernstrom, Althea K. Nagai, and Russell Nieli. 2012. "Brief in Support of Petitioners as Amici Curiae." Fisher vs. University of Texas, U.S. 11-345.

Tolsma, Jochem, Tom van der Meer, and Maurice Gesthuizen. 2009. “The Impact of Neighbourhood and Municipality Characteristics on Social Cohesion in the Netherlands." Acta Politica 44(3):286-313.

Uslaner, Eric M. 2010. "Segregation, Mistrust, and Minorities." Ethnicities 10(4):415-434.

Uslaner, Eric M. 2012. Segregation and Mistrust: Diversity, Isolation, and Social Cohesion. Cambridge, UK: Cambridge University Press. 
van der Meer, Tom and Jochem Tolsma. 2014. "Ethnic Diversity and Its Effects on Social Cohesion." Annual Review of Sociology 40:459-478.

Vigdor, Jacob L. 2004. "Community Composition and Collective Action: Analyzing Initial Mail Response to the 2000 Census." The Review of Economics and Statistics 86(1):303-312.

Winter, Fabian and Nan Zhang. 2018. "Social Norm Enforcement in Ethnically Diverse Communities." Proceedings of the National Academy of Sciences 115(11):2722-2727.

Zhang, Wenquan and John R. Logan. 2016. "Global Neighborhoods: Beyond the Multiethnic Metropolis.” Demography 53(6):1933-1953. 